\title{
A cidade de São Paulo e - Mesmo (entre Ruffato, Runia e Tom Zé)
}

\section{Pedro Dolabela Chagas}

Resumo: O artigo analisa Eles eram muitos cavalos, de Luiz Ruffato, a partir da cidade de São Paulo metaforizada como o "Mesmo", para que com isso compreendamos a ficcionalizaçầo da cidade "física" como alavanca da "crítica da cultura" empreendida pelo autor. Esses resultados são submetidos a um diälogo do conceito de "presença", conforme desenvolvido pelo historiador Eelco Runia, para que seja trazida à luz a carga de redundància da "critica" a São Paulo/Brasil sugerida por Ruffato. Por fim, uma via alternativa a essa redundância é buscada na comicidade de algumas cançôes de Tom Zé, que têm a mesma São Paulo como cenário. Palavras-chave: Luiz Ruffato, Tom Zé, redundância.

Abstract: The article analyzes Eles eram muitos cavalos, by Luiz Ruffato, from the standpoint of a city of São Paulo metaphorically defined as the "Same". The goal is to understand the fictionalization of the "physical" city as decisive for the "critique of culture" produced by the author. These results are submitted to a dialogue with the concept of "presence" as developed by the historian Eelco Runia, in order to clarify the redundancy of Ruffato's "critique" of Sào Paulo/Brazil. Finally, an alternative to that redundancy is found in the humor of Tom Zés compositions - songs that have the same São Paulo as their theme. Keywords: Luiz Ruffato, Tom Zè, redundancy. 


\section{Visão geográfica do Mesmo}

Um estrangeiro vê a cidade de São Paulo pela primeira vez. Ela vai-lhe surgindo como o desenrolar contínuo de vias muito longas, ocupadas por uma massa de edificações muito semelhantes, alinhadas ao longo dessas ruas e avenidas quase idênticas que, espalhando-se pelo território gigantesco, organizam o (pesadíssimo) fluxo pelo Mesmo.

E o Mesmo, aqui, num sentido estritamente geográfico: uma única lógica estendida ao espaço indefinido, sem contornos ou limites visíveis, que se espalha e se autoprocria num movimento perpétuo de propagação, de avanço. Para o olhar não iniciado, é quase impossível reconhecer camadas, recortar no Mesmo temporalidades indicativas de uma História: parece que todos os diferentes séculos de vida da cidade foram suplantados por uma única Quantidade - essa Quantidade massiva, onipresente, que parece não encontrar qualquer força contrária à sua disseminação, fazendo com que o percurso por ela seja a experiência intensiva de uma única (mas absoluta) constante: a massa, a carga, o peso, o barulho de frequência ininterrupta, a continuidade e a sequência linear (porém muito densa) de edifícios, edifícios, edifícios... Afora o parque (gigantesco e único), o território não é pontuado, não é organizado por elementos que catalisem o olhar indicando caminhos ou direções. E ele não acaba nunca.

\section{Visão crítica do Mesmo}

Mas em Eles eram muitos cavalos, de Luiz Ruffato, São Paulo não apresenta essa homogeneidade. Que a obra focaliza a cidade de São Paulo está claro; a narração o escancara logo na primeira micronarrativa (das setenta que a compõem), que, intitulada "Cabeçalho", consta apenas das duas frases: "São Paulo, 9 de maio de 2000. Terça-feira". Logo de saída, a megalópole vem localizar espacialmente aquele complexo de narrativas interdependentes, sendo justamente essa precisão geográfica o que lhes confere unidade (o que não poderia advir de um "enredo", que sequer existe naquela sequência de narrativas que, em conjunto, não constituem um romance). "Paulistanas" (além de "brasileiras", é claro, mas veremos logo que há nelas uma especificidade local que não é suplantada pela sua remissão à realidade social do

1 RUfFATO, Luiz. Eles eram muitos cavalos. São Paulo: Boitempo, 2001, p. 11. 
país como um todo: a visão crítica não suplanta a visão geográfica do Mesmo; pelo contrário, ela a pressupõe), essas narrativas dispõem camadas sobre a cidade-Mesmo - camadas essencialmente sociais, e é importante que esse ponto não passe em branco: não são camadas, por exemplo, históricas, mas sim socioeconômicas. Quando permeadas pelo elemento temporal, elas remeterão apenas às diferentes temporalidades que, medidas em função do seu grau de integração ao habitus sociocultural estimulado pelo sistema econômico regente (com seus padrões estipulados de vocabulário, comportamento, expectativas e consumo), constituem a assincronia do Brasil atual: a miríade de diferentes microcosmos sociais, com os seus múltiplos modos de vida.

É assim que, logo de saída, a figura medíocre do executivo braço de ferro que controla o caixa dois do empresário inescrupuloso ("um apartamento enorme em Moema um por andar três suítes contratei um desses veados dinheiro não é problema ele montou um circo o mulherio estranha aí eu falo a decoração é do fulano elas têm um orgasmo") convive com a do trabalhador braçal paupérrimo ("Tem dez anos que vou a pé. É uma economia danada no final do mês"). ${ }^{3}$ Os tipos (porque são tipos, afinal) vão se seguindo: o mendigo (que é assassinado numa chacina de rotina), a atriz alcoólatra e decadente, a mulher humilhada pelo ex-marido... Em seguidos flashes cotidianos a São Paulo de Ruffato vai surgindo, em seu vendaval de microcosmos, como um ente multifacetado - mas será que essa diferenciação significa dizer que Ruffato nega o Mesmo como signo para a sua leitura? Se não, onde ele o situa?

A resposta estaria em que, em Eles eram muitos cavalos, todas as diferentes sequências remetem ao Mesmo como o plano que as organiza verticalmente e as distribui espacialmente, predeterminando as suas ocupações do espaço e as suas expectativas de futuro (que ficam evidentes nas sugestões de um narrador heterogêneo à imanência social que descreve). Na obra de Ruffato a vizinhança e a sucessão de tipos perspectiviza o seu copertencimento a uma única imanência - que, na organização da obra, não pode ser outra senão a própria cidade de São Paulo, tomada como sinédoque do país. No vocabulário deste ensaio, essa imanência, esse Uno ao qual remetem todas as micronarrativas de Eles eram muitos cavalos, é o Mesmo - mas não mais (ou não mais apenas) uma visão geográfica do Mesmo, e sim uma visão crítica. Tomamos aqui a palavra "crítica" num sentido estrito, como a problematização de um estado de coisas que sugere a necessidade da sua reversão num

2 Idem, ibidem, p. 13.

3 Idem, ibidem, p. 14.

270 CHAGAS, Pedro Dolabela. A cidade de São Paulo e o mesmo 
futuro mais ou menos incerto. Num sentido mais amplo, a englobar a importante história do termo dentro do pensamento moderno, em seus extremos a "crítica" produziu definições do futuro tanto como o momento utópico de superação das insuficiências da atualidade (tal foi o grito tanto da Revolução Francesa quanto daquelas direta ou indiretamente motivadas pelo Manifesto Comunista), quanto como o horizonte de bloqueio das possibilidades de reversão das insuficiências (encaixa-se aqui a Teoria Crítica de Theodor Adorno, já totalmente descrente de que o sistema, como estrutura de dominação, possa ser algum dia eliminado). Em Eles eram muitos cavalos o futuro se alinha nessa segunda descrição, pois nele se prevê, ao fim e ao cabo, a permanência e continuidade do Mesmo, alçado à posição de índice definidor não apenas da cidade de São Paulo, mas da sociedade brasileira em geral. Complexa, nossa sociedade seria, todavia, composta por estratos que reproduzem o Mesmo a partir da sua própria autopreservação, um Mesmo que, reciprocamente, se alimenta das diferenças para se autoproduzir, num processo ininterrupto e irreversível: não se nota, na obra, a presença de alguma força que favoreça o movimento contrário.

\section{A crítica como repetição}

Tem-se então que o Mesmo, num sentido crítico ou sistêmico - e não apenas geográfico -, se presentifica em Eles eram muitos cavalos.

O verbo "presentificar" merece uma observação detida. Nós o tomamos da teoria da "presença" desenvolvida por Eelco Runia (professor da Universidade de Groningen), um teórico da História ainda desconhecido no Brasil. Pensemos na tese central de seu texto "Forget about it': 'parallel processing' in the Srebrenica report" ["Esqueçam-se disso': 'processamento paralelo' no relatório de Srebrenica”], segundo a qual o grupo de pesquisadores contratado pelo governo da Holanda para investigar os fatos ocorridos em 1995 no enclave de Srebrenica, na Bósnia - quando o grupamento militar holandês que o protegia (sob o encargo da ONU) foi incapaz de conter o massacre de milhares de bósnios muçulmanos pelo exército sérvio -, repetiu ou reproduziu inúmeras das ações que haviam determinado o fracasso da operação militar para cuja investigação eles tinham sido contratados. A Brigada Aéreo-Móvel (em inglês, Air Mobile Brigade) foi a unidade do exército batavo destacada em 1993 para a Bósnia; três anos mais tarde, J. C. H. Blom foi o historiador destacado pelo governo para a condução da pesquisa sobre as razões do fracasso da operação; em 
2002, veio à tona o resultado da pesquisa - um documento totalizando exatas 3.394 páginas. Interessa-nos pinçar aqui, da interpretação sugerida por Runia do processo de condução da pesquisa, o modo como a presença do acontecimento passado determinou a relação que os pesquisadores estabeleceram com ele. Numa série impressionante de reproduções das ações do governo holandês e da Brigada Aéreo-Móvel nos momentos críticos dos acontecimentos analisados, Runia observa que os pesquisadores 1) "took the same high moral ground as the one from which the Dutch Srebrenica policy had been conducted"; 2) "copied the mode of operation [...] a combination of willful unpreparedness, lack of interest in the big picture, improvisation, and a hands-on approach"; 3 ) "replicated the logistic predicament of the Air Mobile Brigade"; 4) "by replicating the recruitment policy of the Air Mobile Brigade, [they] came to embody some of the very problems it was supposed to study"; 5) [they reproduced] "the [Brigade's] style of leadership"; 6) [they] "created [their] own enclave. [...] Not only were the borders with the outside world made as impermeable as possible, the researchers also behaved as if they were surrounded by enemies"; 7) [they] "copied the combination of protraction, exhaustion, and frenzy that characterized the time frame of the Srebrenica mission." ${ }^{4}$ Diante desse vendaval de reproduções, a tese de Runia é a de que a História, ao invés de corresponder meramente à factualidade de um passado já indelevelmente descolado do presente, é, na verdade, uma presença que, atuante na atualidade, age para moldar, ou codeterminar, nossa relação para com os fatos dos quais nos aproximamos: o passado confere certa forma - a sua forma específica - à aproximação que dele fazemos.

Essa hipótese tem como referência o fenômeno psicanalítico do "processamento paralelo" (parallel processing): o momento em que o paciente reproduz, em suas ações, as ações (de outrem) que o haviam perturbado: “[...] parallel processes are subconscious

4 1) "assumiram a mesma posição moralmente elevada com que a política holandesa em Srebrenica havia sido conduzida"; 2) "copiaram o modo de operação [...] uma combinação de despreparo, falta de interesse no quadro geral, improvisaçāo, e uma abordagem de tipo 'mão na massa"; 3) "reproduziram as dificuldades logísticas da Brigada Aéreo-Móvel"; 4) "ao reproduzir a política de recrutamento da Brigada Aéreo-Móvel, acabaram encarnando alguns dos problemas que deveriam estar estudando"; 5) [reproduziram] "o estilo de liderança [da Brigada]"; 6) "criaram [seu] próprio enclave. [...] Não apenas as fronteiras com o mundo exterior foram tornadas o mais impermeáveis possivel, mas também os pesquisadores se comportavam como se estivessem cercados por inimigos"; 7) "copiaram a combinação de prostração, exaustão e frenesi que caracterizou temporalmente a missão de Srebrenica." RUNIA, Eelco. 'Forget about it': 'parallel processing' in the Srebrenica report. History and theory, Middletown: Wesleyan University/Wiley-Backwell Publishing, n. 43, p. 303-308, October 2004.

272. CHAGAS, Pedro Dolabela. A cidade de São Paulo e o mesmo 
reenactments of past events: when you are caught up in a parallel process, your behaviour repeats key aspects of what there is to know about what you're studying - in a way, however, that you yourself don't understand". Em outras palavras, o fenômeno corresponde à reprodução do padrão do evento perturbador, que desse modo se presentifica - se prolonga - na atualidade, justamente quando o paciente psicanalítico parecia estar dele se distanciando para melhor analisá-lo. É exatamente nesse ponto, em que o distanciamento do passado procura assumir a forma da objetividade, que o parallel processing faz com que a forma da "objetividade" no presente venha incorporar a forma peculiar à do evento passado - que então se torna novamente presente. Para o trabalho do historiador profissional, essa espécie de identificação pode trazer as implicações seguintes:

Being in themselves neither good nor bad, identifications may, however, diminish the quality of description and analysis when [...] their metaphorical provisionality (enabling the subject to understand the object in terms of the subject) somehow gets lost. In such cases, the identifications submerge and assume a life of their own [...] only to emerge, sooner or later, as acting out, or, as I have called them, "provocations". 6

Fenômeno da ordem da emergência, a "presença" escapa ao controle do observador para vir à tona no campo observado: "Chances are that in their provocations the researchers repeated [...] the problems they studied. It might be supposed that in these provocations they enacted those aspects of the 'dramatic developments' of July 1995 that were too bound up with themselves - be it as historians, as men and women, or as Dutch citizens". Os acontecimentos que estavam "too bound up with

5 "[...] processamentos paralelos são reencenações subconscientes de eventos passados: quando você é pego num processamento paralelo, seu comportamento repete aspectos-chave daquilo que interessa saber a respeito daquilo que você está estudando - de uma maneira, entretanto, que você mesmo não entende." Idem, ibidem, p. 295.

6 "Sendo em si mesmas nem boas nem ruins, as identificaçōes podem, entretanto, diminuir a qualidade da descrição e da análise quando [...] sua provisão metafórica (que permite ao sujeito entender o objeto nos termos do sujeito) de algum modo se perde. Nesses casos, as identificações submergem e assumem vida própria [...] emergindo, mais cedo ou mais tarde, como atuações ou, conforme eu as denominei, 'provocações'." Idem, ibidem, p. 309.

7 "É provável que em suas provocaçōes os pesquisadores repetiram [...] os problemas que estavam estudando. Pode-se supor que nessas provocaçōes eles encenaram aqueles aspectos dos 'desdobramentos dramáticos' de julho de 1995 nos quais estavam demasiadamente envolvidos - seja como historiadores, como homens e mulheres, ou como cidadãos holandeses." Idem, ibidem, p. 311. 
themselves" (aqueles nos quais os pesquisadores estavam envolvidos afetivamente num grau tão elevado a ponto de lhes impossibilitar qualquer tipo de distanciamento) acabam então por serem reencenados. E para voltarmos rapidamente ao nosso assunto original, fazendo uma ponte entre o tratamento historiográfico do passado e a ficcionalização do presente (na história e na literatura, produções narrativas decerto diferentes, mas que podemos supor permitirem a emergência do fenômeno da presença de formas semelhantes, se não idênticas), podemos pensar então que, se o Mesmo que condiciona a lógica de autoprodução e autopreservação da São Paulo/Brasil é visto criticamente por Ruffato, é igualmente certo que Ruffato reproduz, em Eles eram muitos cavalos, a própria lógica que ele parece criticar. Pois se o diverso trabalha (inclusive apesar de si próprio) para a autorreprodução do Mesmo, e se o Mesmo é, desse modo, estruturalmente inevitável (ele é na verdade o pressuposto de cada um dos microcosmos, tal como o corpo obrigatoriamente o é para os órgãos que o compõem), as diferenças são abafadas como poder diferenciador - e as camadas do Mesmo nada mais são do que o próprio Mesmo se atualizando de formas contiguamente diferentes entre si. É justamente aí que, no momento em que parecia lançar uma mirada crítica à "razão" que instrumentaliza a permanência do sistema-Mesmo, Ruffato repete o pressuposto, implícito nessa mesma "razão", segundo o qual a realidade é "infelizmente inalterável", por serem inalteráveis os "fundamentos do sistema". Não é o pressuposto da inalterabilidade do sistema exatamente o que subjaz ao pensamento simetricamente oposto à crítica, isto é, ao pensamento "conservador"? Pensemos na insistência exasperadora com que a tecnocracia econômica do Governo Federal tem afirmado a impossibilidade de alteração dos fundamentos da economia brasileira desde a implementação definitiva do Plano Real em 1994. Contra a percepção disseminada da necessidade urgente de reformas, caracteriza o discurso dessa racionalidade a convicção irremovível na necessidade da preservação integral do sistema atual, além do seu desprezo - a sua arrogante condescendência - em relação aos que acreditam na possibilidade da mudança: esses seriam ignorantes, ou simplesmente ingênuos.

Sob essa luz, Eles eram muitos cavalos aparece como um prolongamento do fatalismo que tão ordinariamente prevê a impossibilidade de reversão das disposições atuais da sociedade brasileira: a "crítica" que postula a inalterabilidade da matriz do sistema reproduz, ao fim e ao cabo, a própria vontade de prosseguimento dessa matriz pelo discurso "conservador" 


\section{A metonímia rotinizada como "conhecimento comum"}

Há ainda outra teorização da "presença" em Eelco Runia: a presença como um efeito de superfície que torna o passado presente no texto que o investiga, não como "processamento paralelo", mas sim como construção metonímica. Enquanto o primeiro seria mais tipicamente associado à resposta ao evento traumático, a metonímia concerne à reverberação dos padrões culturais consolidados: pois ela age sorrateiramente, em silêncio, desviando qualquer atenção que possa recair sobre si mesma, sendo o seu efeito produzido, acima de tudo, pela desatenção - pelo estímulo ao acervo pré-disponível de "conhecimento comum". Na comparação com a metáfora,

metonymy is much better at communicating what I have called "common knowledge". Or, to be more precise: metonymy is better at suggesting that what it conveys is "common knowledge". Metaphor, on the other hand, specializes in bringing about a sense of personal comprehension. A metaphorical text draws attention to itself, [...] and, by doing so, invites interpretation. [...] This indeed is what metaphor does: it forfeits the possibility of instilling "common knowledge" and instead devotes itself entirely to inspiring the sensation that something "out there" is comprehended. ${ }^{8}$

A diferença estaria em que a metonímia esconde a sua origem metafórica, colocando-se como pretensamente autoevidente (tão autoevidente quanto a substituição de "realeza" por "coroa"):

With metonymy, things are quite different. Metonymy is the trope of dissimulation. Metonymy wants us to believe that it imparts only one "meaning" - the truth, that this

"meaning" lies right at the surface, and that this one "meaning" is all that it conveys. Because it suggests that it has nothing to hide, metonymy denies that it needs to be interpreted. [...] Insofar as it succeeds in doing so, the knowledge it imparts is "common knowledge".

8 “'A] metonímia é muito melhor para comunicar aquilo que denominei 'conhecimento comum'. Ou, para ser mais preciso: a metonímia é melhor em sugerir que o que ela comunica é conhecimento comum'. A metáfora, por sua vez, se especializa em produzir uma impressāo de compreensāo pessoal. O texto metafórico chama a atençāo para si [...] e, ao fazê-lo, convida à interpretação. [...] Isso de fato é o que a metáfora faz: ela abandona a possibilidade de instilar 'conhecimento comum' e, ao invés disso, devota-se inteiramente a inspirar a sensação de que algo 'exterior' foi compreendido." Idem, ibidem, p. 313.

9 "Com a metonímia, as coisas são muito diferentes. A metonímia é o tropo da dissimulação. A metonímia quer fazer-nos acreditar que ela carrega apenas um 'significado' - a verdade -, que esse "significado" está localizado 
Se nesse ponto a teorização de Runia pode adequar-se à análise de Eles eram muitos cavalos, fica claro então o modo pelo qual as metonímias de Ruffato conseguem autossugestionar-se como verdade. Ninguém, entre o público intelectualizado do Brasil contemporâneo (leitor potencial da sua obra), duvida da brutalidade da polícia, da miséria dos favelados, da mediocridade das classes médias, da responsabilidade das "elites" (com a cumplicidade das classes médias) pela produção e manutenção do atual estado de coisas - assim como ninguém duvida da densidade do horror, e da dificuldade da sua reversão. A atribuição de papéis é, desse modo, estável, e assim é possível a Ruffato utilizar, por exemplo, a representação da estante de uma biblioteca particular e o cardápio de um restaurante elegante para espacializar os estratos sociais que supostamente orientam a continuidade bárbara do Mesmo em suas disposições constitutivas: a estante contém os best-sellers do momento e as obras evidentemente não lidas (Ilusões, de Richard Bach, ao lado de O vermelho e o negro, de Stendhal), os livros sobre guerra e os livros de autoajuda pessoal e profissional (O preço da guerra, de um lado, e Fases de vida, Ajuda-te pela psiquiatria e Gerência de marketing, de outro, ${ }^{10}$ enquanto o cardápio do restaurante grã-fino traz uma "salada de aspargo fresca com medalhão de lagostas e endívias", ovas de salmão, sobremesa de "sorvete de creme e maracujá com cúpula de caramelo"... $\mathrm{A}$ estratégia é fazer a mediocridade saltar à vista através do simples deslocamento dos "objetos" (sob o procedimento da colagem ou do ready-made) de seu contexto original, o que entretanto só consegue alcançar o significado crítico almejado, além de poder ser utilizado (como procedimento) com tanta segurança, dada a pressuposição pelo autor da interpretação crítica desses objetos como um common knowledge da comunidade de leitores que Eles eram muitos cavalos pretende alcançar. A presença de uma interpretação pontual da sociedade brasileira se insinua aí disfarçada de obviedade, pois é justamente o seu estatuto de obviedade que ela vem conclamar: "'presence' can be regarded as a form of 'common knowledge', as a jumble of 'public secrets', a huge sphere of [...] 'ideas without a subject"':"2

logo na superfície, e que esse único'significado'é tudo o que ela comunica. Porque ela sugere não ter nada a esconder, a metonímia nega que ela precisa ser interpretada. [...] Na medida em que ela é bem-sucedida em fazê-lo, o conhecimento que ela transmite é conhecimento comum." Idem, ibidem, p. 313-314.

10 RUFFATO, Luiz. Eles eram muitos cavalos, op. cit., p. 51-52.

11 Idem, ibidem, p. 146.

12 "A 'presença' pode ser entendida como uma forma de 'conhecimento comum', como um arrazoado de 'segredos públicos', uma enorme esfera de [...] 'ideias sem sujeito'."

276. CHAGAS, Pedro Dolabela. A cidade de São Paulo e o mesmo 
Presence succeeds in going unnoticed not because it is hidden from view, but because it coincides with our culture. In a sense it is our culture. Culture, after all, is the set of things we do not have to talk about, our private collection of public secrets. As common knowledge, presence is indestructible - and because it cannot be remembered it is also unforgettable. ${ }^{13}$

Desse modo Ruffato repete mais uma vez a São Paulo/Brasil que ficcionaliza - agora exatamente não mais por repetir aquilo que podemos caracterizar como a contraface do discurso conservador, mas por repetir uma hermenêutica social já consagrada medianamente: ao mesmo tempo em que delega funções e papéis diferentes a cada um dos agentes sociais representados (onde consta a velha simpatia pela pobreza e a velha crítica moral ao dinheiro), Eles eram muitos cavalos mais uma vez sugere - pelo determinismo na atribuição de lugares e funções e pela ausência de alternativas a ele - a inevitabilidade do atual estado de coisas. O seu "realismo" reproduz, desse modo, certo imaginário corrente relativo a São Paulo/Brasil, imaginário que, como tal, corresponde ao máximo de substância ontológica que um país pode ter - pois "What makes a nation is not its story about itself, but the variety of ways in which its past can force it - and enable it - to rewrite its story about itself" 14 O caso, então, é que as possibilidades de escritura da história são, a todo instante, parcialmente bloqueadas pelo quadro metonímico tornado "conhecimento comum". Não seria a São Paulo de Ruffato indicativa de uma limitação dessa ordem?

Mas se limitações dessa ordem existem, isso entretanto não implica a inexistência de contraexemplos. Podemos dar um passo atrás, e investigar como São Paulo - a mesma cidade construída - pode suscitar, porque já suscitou, construções imaginativas diferentes da tragicidade implicada na imagem do Mesmo. Voltemos à cidade de São Paulo como solo fundador (sinedóquico) das metonímias de Ruffato sobre a realidade social brasileira; voltemos às suas especificidades, para delas posteriormente

13 "A presença é bem-sucedida em passar despercebida não por estar escondida, mas por coincidir com a nossa cultura. Num certo sentido ela é a nossa cultura. A cultura, afinal de contas, é o conjunto de coisas a respeito de que nós não temos que falar, a nossa coleçāo particular de segredos públicos. Como conhecimento comum, a presença é indestrutivel - e porque ela não pode ser lembrada ela é também inesquecivel." RUNIA, Eelco. Spots of time. In: History and theory, Middletown: Wesleyan University/Wiley-Backwell Publishing, n. 45. p. 314-316, October 2006.

14 "O que faz uma nação não é a sua estória a respeito de si mesma, mas a variedade de maneiras pelas quais o seu passado pode forçá-la - e possibilitá-la - a reescrever a sua estória a respeito de si mesma." Idem, ibidem, p. 311. 
regressarmos ao Brasil como tema dominante. Conforme vínhamos sugerindo, Eles eram muitos cavalos revela algo da peculiaridade de São Paulo dentre as demais metró-

poles brasileiras; todavia, essa mesma corporeidade, esse mesmo fato geográfico-espacial já suscitou imagens em que o Mesmo não existe. Será que, em casos como esse, São Paulo deixa de ser São Paulo - ou o Brasil deixa de ser Brasil?

\section{O fundamento geográfico da visão crítica do Mesmo}

Até aqui viemos projetando uma imagem da paisagem física de São Paulo próxima à impressão recorrente que dela faz o observador não iniciado, ainda não instrumentalizado para ler as múltiplas diferenças que a permeiam. É difícil imaginar que os paulistanos concordem integralmente com essa descrição. E eles estão certos, pois o observador iniciado sabe perfeitamente que entre o Campo Belo e o Cambuci, entre Pinheiros e Cerqueira César, entre o Morumbi e a Pompeia pouca semelhança pode haver. As diferenças não se restringem aos agrupamentos humanos, pois a cidade construída em si possui uma variabilidade vertiginosa. Porém isso nada impede que a presença específica de São Paulo - e não de qualquer outra metrópole brasileira - se faça sentir em Eles eram muitos cavalos: independentemente da sua variabilidade interna (que a obra observa bem), importa perceber que, na experiência urbana brasileira, a São Paulo geográfica favorece mais do que qualquer outra cidade a visão crítica do Mesmo.

O caso, aqui, diz respeito ao tamanho. Ao aumentar enormemente o distanciamento entre as diferenças, ao disseminar pelo território incontáveis quilômetros quadrados de bairros que produzem gradações lentas entre as diferentes classes sociais, ao impor a apreciação de mudanças na paisagem apenas através do deslocamento interminável por suas avenidas, São Paulo mitiga a percepção majoritariamente definidora da experiência social na cidade grande brasileira: a experiência do contraste, do choque abrupto, que em São Paulo aparece diminuída. Rio e São Paulo não poderiam, nesse ponto, ter se tornado mais diferentes: com suas favelas que se erguem imediatamente por detrás dos bairros mais abastados, o Rio de Janeiro é, por excelência, a sinédoque do Brasil como uma terra de antagonismos. A Zona Sul do Rio situa imediatamente o seu morador como não morador da favela, "nós" e "eles" em absoluto contraste; São Paulo, por sua vez, representa a progressão (não menos tensa e violenta, é óbvio) das gradações, que desse modo podem ser apreciadas (ou melhor: sentidas) em si. Essa especificidade corresponde, grosso 
modo, à diferença entre Eles eram muitos cavalos e Cidade de Deus, de Paulo Lins: neste, tem-se a guerra imediata; naquele, tem-se a panela de pressão permanentemente à beira da explosão. São Paulo favorece, ao fim e ao cabo, a visão das diferenças pelos olhos das "classes médias" (situadas imprecisamente nalgum lugar entre a madame que compra um vestido de seis mil reais na rua Oscar Freire e a miséria do Capão Redondo), ao passo que o Rio, caracterizado por uma estratificação social muito semelhante, entretanto dispõe automaticamente a classe média como alteridade absoluta em relação à sua vizinhança miserável - produzindo destaques e recortes muito mais urgentes do que os de São Paulo.

Mas com isso nada respondemos sobre a possibilidade, indagada ao final do item anterior, da perspectivização de uma São Paulo não condicionada pelo Mesmo - da imaginação de uma São Paulo que não tenha o Mesmo como princípio ativo ordenador. Que haja diversidade em São Paulo, ou que nela nossos contrastes sociais sejam mitigados pela sua extensão no espaço, nenhuma dessas hipóteses anula o Mesmo como termo de referência - pelo contrário, ambas continuam dialogando com ele. Em direção contraposta, a pergunta mais acima especulava sobre a possibilidade da imaginação de uma São Paulo que seja alheia àquela metáfora. Seria o caso, então, de pensar a megalópole fora da compulsão à crítica social e à representação da realidade social (mas não necessariamente indiferente a elas); seria o caso de pensá-la de maneira não obrigatoriamente comprometida com os problemas da nossa atualidade, nem com a necessidade (e eventual impossibilidade) da sua transformação futura. Seria o caso, afinal, de pensá-la externamente à crítica como compromisso intelectual dominante.

\section{Uma visão não crítica de São Paulo faria dela, ainda assim, o Mesmo?}

Certamente a imaginação (ou invenção) dessa São Paulo acontece várias vezes todos os dias da semana, pois a São Paulo desvinculada do Mesmo compreende, principalmente, aquela que se autoproduz sem teorizar a si mesma: o próprio movimento de autoprodução da megalópole compreendido não negativamente (como algo que obedece a uma lógica determinada por instâncias hierarquicamente dominantes, e heterogênea ao restante das trocas sociais - como o sugere a noção de "classe dominante"), mas sim afirmativamente (em sua vitalidade própria, que não obedece a uma orientação unívoca, sendo ademais capaz de se adaptar criativamente às limitações que a contingência impõe ao movimento). Assim como em qualquer outro lugar, em São Paulo as rotinas não são estáticas, elas não simplesmente reiteram as limitações do 
dado: pelo contrário, modificam o dado no seu próprio processo de repetição. Daí que "tipos" sejam, ao fim e ao cabo, fracas aproximações de um estado de coisas objetivado, pois não observam a atuação das forças da diferenciação e da variabilidade, estando acima de tudo preocupados - quando é da crítica social que se trata - em estabelecer uma organização ideologicamente motivada do campo observado.

Mas não queremos apelar a nenhum empirismo aqui; para imaginarmos uma alternativa à crítica numa visão de São Paulo que seja, no mínimo, mais afeita ou mais apta a cotejar aquilo que caracterizamos como a sua "invenção cotidiana" (não orientada ou pré-programada por uma lógica heterogênea à própria imanência das trocas), ficaremos na esfera do texto. Convocamos então o Tom Zé de Se o caso é chorar, provavelmente seu disco mais paulistano. Nele, o Mesmo é convocado a rir, mesmo quando o compositor lança mão de algum "tipo" - como quando ao "Senhor cidadão" (uma canção que principia pela leitura do poema "Cidade", de Augusto de Campos), que identificamos como uma tipificação dos moradores da cidade que agem para dar continuidade às rotinas mais espúrias que ela apresenta, é lançada a pergunta:

Oh senhor cidadão/eu quero saber, eu quero saber

com quantos quilos de medo/com quantos quilos de medo

se faz uma tradição?

Oh senhor cidadão/eu quero saber, eu quero saber

com quantas mortes no peito/com quantas mortes no peito se faz a seriedade?

A canção subsequente ("A briga do Edifício Itália e do Hilton Hotel"), por sua vez, fala da cizânia entre duas construções célebres do centro da cidade:

E o Hilton sorridente/disse que o Edifício Itália tem um jeito de Sansão descabelado/e ainda mais, só pensa em dinheiro não sabe o que é amor/tem corpo de aço, alma de robô/porque coração ele não tem pra mostrar Pois o que bate no seu peito/é máquina de somar. O Edifício Itália sapateou de raiva/rogou praga e até insinuou que o Hilton/tinha nascido redondo pra chamar a atenção/abusava das curvas pra fazer sensação/e até parecia uma menina louca ou a torre de Pisa/vestida de noiva. 
Assim como Eles eram muitos cavalos, Se o caso é chorar tem São Paulo como centro de referência. Mas em Tom Zé os movimentos da cidade não parecem pressupor uma lógica unívoca de agenciamento. Não parece haver uma síntese capaz de organizar essas visões da cidade, uma lógica unívoca que as subsuma - essa cidade seria o Mesmo, ainda assim?

Existe alguma projeção de futuro na São Paulo de Tom Zé, e um futuro especialmente ruim surgirá numa canção de seu disco subsequente Todos os olhos que descreve um cenário tristemente familiar:

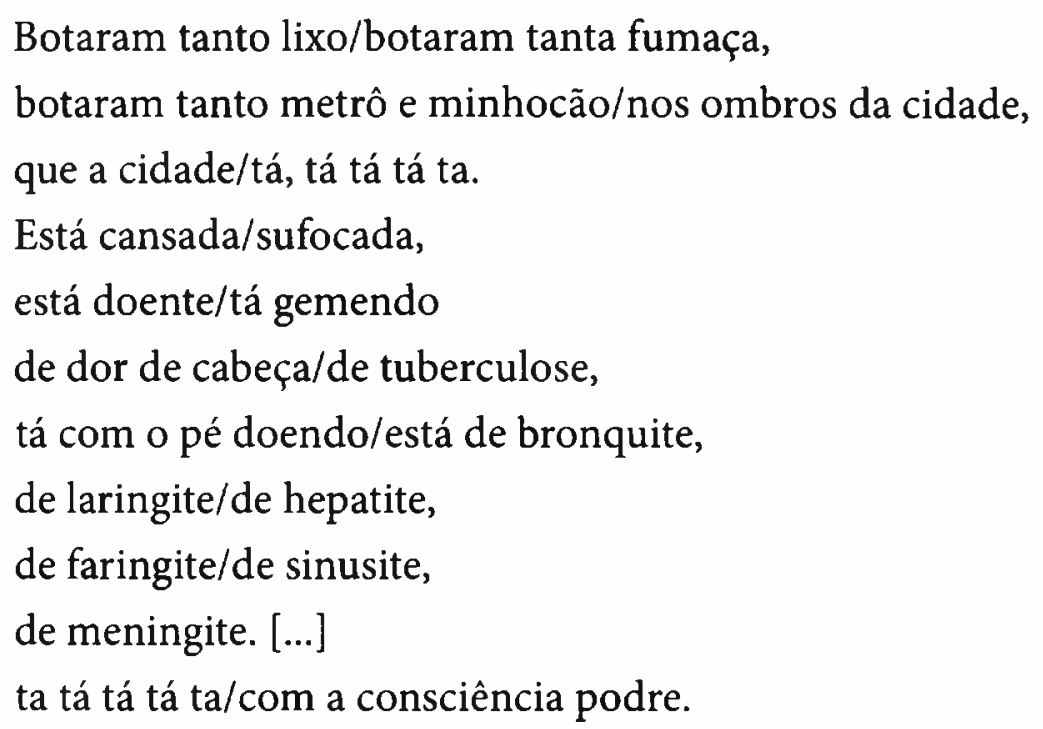

Mas essa visão crítica do presente e do futuro permite espaço para o jogo e para o riso. Não representaria esse riso descompromissado com o fatalismo a reversão mais do que a mera "oposição" - da imagem do Mesmo como inevitabilidade sistêmica? Não seria ele, exatamente por isso, o contrário do pessimismo - sem que isso implique um compromisso menor com o estrato que o humor, nesse caso, critica? Mas mesmo a crítica não funciona aqui como um princípio universal; em Tom Zé - e isso é importante - ela não gera um princípio absoluto. Para além do fato de ela vir em si permeada pela dicção cômica - o que já a distancia da carga excessiva do Mesmo -, ela compartilha um espaço imagético comum com composições que não lhe dão sequência, como no caso da briga entre o Edifício Itália e o Hilton Hotel. Se a compararmos às metonímias regentes de Eles eram muitos cavalos, ter-se-á, de um lado, a autoprodução do Mesmo como indicativo da sua permanência indefinida no tempo e, de outro, o espaço para a comicidade que não procura alcançar nada para além de si mesma, em seu acontecimento puro. Mais do que isso: no momento em que o Edifício Itália e o Hilton Hotel são individuados como 
objeto de uma brincadeira em meio à "selva de pedra", eles são concomitantemente revelados como parte do patrimônio afetivo do ouvinte, mesmo que o ouvinte não saiba disso - pois é possível imaginar que a composição de Tom Zé, por si, venha a despertar nele essa revelação.

Sob essa perspectiva, a São Paulo de Tom Zé não é a mesma de Ruffato. Se assim é, não fica então evidente que o Mesmo não é, porque não pode ser, a única metáfora válida para a apreensão da megalópole - ou para a sua conceitualização?

\section{Ideias impedem a implosão do Mesmo}

A metáfora de São Paulo como o Mesmo não existia para o Mário de Andrade de Pauliceia desvairada - pelo contrário, o que se vê ali são séries de instantâneos que não remetem a um núcleo gerador comum. Anos de especulação imobiliária mais tarde, quando a novela de Janete Clair foi ao ar (em 1972, mesmo ano de lançamento de Se o caso é chorar, sendo completada em 1973, mesmo ano de Todos os olhos), a metáfora da "selva de pedra" já se tornara de fácil penetração. Tom Zé, contemporâneo (mas não companheiro) de Janete Clair, à sua maneira também a afirmou. Nas décadas seguintes, a miséria social brasileira converteu a metáfora do Mesmo numa espécie de signo da derrocada: aqui se encaixa Eles eram muitos cavalos.

Mas o que fazer com as metonímias de Tom Zé, aquelas que tratavam com carinho os "imensos blocos de concreto" da canção de Paulinho da Viola (lançada em 1975, "Amor à natureza" lamentava o impacto da selvageria imobiliária na cidade do Rio de Janeiro), e que ridicularizavam a seriedade e a tristeza do cidadão cinzento? O que fazer com a canção que não ri apenas da, mas também na poluição ambiental? Nós estamos preparados para entender São Paulo desse modo? Estamos dispostos a ver uma São Paulo feliz - simplesmente feliz, e não essencialmente feliz (como consta na idealização de si mesmos que os brasileiros insistem em promover) -, e metaforizar essa felicidade? Nós, afinal, concedemos a São Paulo - e ao Brasil - o direito a uma interpretação que não seja rigorosamente marcada pela crítica social? Fica marcada, nas metonímias que imediatamente parecem dizer toda a verdade sobre aquilo que somos, a obsessão com o Mesmo - e o que fazer com Tom Zé, então? Uma possibilidade é falarmos sobre a sua loucura, o seu espalhafato, o seu talento cômico nato, todas essas noções que nos servem para alocá-lo numa posição de marginalidade quanto à seriedade que, ela sim, penetra no país analiticamente - ao contrário do humor, que apenas (ainda que "maravilhosamente") 
reproduziria, espontaneamente, alguns dos "traços culturais" do "povo brasileiro" - a "alegria", a "informalidade", o "senso de improvisação" - virtudes que entretanto em nada colaborariam para a reversão da atualidade... A conversa poderia continuar indefinidamente.

\section{Coda}

Seria interessante que ou bem deixássemos o Brasil de lado, ou que então substituíssemos a ideia de essência pela de movimento quando falarmos dele. E que não soubéssemos o que esperar dele antes de começar a observá-lo, enfim.

Pedro Dolabela Chagas é professor de Teoria e História Literária na Universidade Estadual do Sudoeste da Bahia. 